\title{
Lesões macroscópicas em órgãos e carcaças de poedeiras comerciais do Agreste de Pernambuco, Brasil
}

\author{
Macroscopic lesions on the organs and carcasses of laying hens in Agreste of \\ Pernambuco, Brazil
}

ALMEIDA, Tássio José de Oliveira. Mestre em Ciências Veterinárias no Semiárido
Universidade Federal do Vale do São Francisco, Campus Ciências Agrárias/E-mail: tassioalmeida@live.com

SANTOS FILHO, Almir Alves dos. Mestrando em Medicina Veterinária

Universidade Federal Rural de Pernambuco, Dep. de Medicina Veterinária/E-mail: almirsfilho@outlook.com

\author{
MACIEL, Cícera Edpaula de Melo. Médica veterinária \\ Universidade Federal Rural de Pernambuco, Unidade Acadêmica de Garanhuns/E-mail: \\ edpaulacemm@gmail.com
}

ROLIM, Maria Betânia de Queiroz. Doutora em Medicina Veterinária

Universidade Federal Rural de Pernambuco, Dep. de Medicina Veterinária/E-mail: mbveterinaria@yahoo.com.br

\section{RESUMO}

O estudo teve como objetivo identificar lesões macroscópicas em órgãos e carcaças de poedeiras comerciais brancas, de granjas avícolas do Agreste de Pernambuco, e discutir a possibilidade de ocorrência de doenças. Poedeiras comerciais foram coletadas até 12 horas após o óbito e transportadas ao Laboratório de Anatomia e Patologia Animal da Unidade Acadêmica de Garanhuns, Universidade Federal Rural de Pernambuco. Realizou-se anamnese minuciosa com tratadores e médicos veterinários das respectivas granjas, com perguntas sobre o lote da ave. Por meio do exame necroscópico, foram verificadas alterações macroscópicas na área externa, cavidade celomática e órgãos de 176 poedeiras, oriundas de quatro granjas. Destas aves, 146 (82,95\%) apresentaram algum achado de necropsia, principalmente nos sistemas digestório $(40,73 \%)$ e respiratório $(37,75 \%)$. Também foram verificadas alterações nos sistemas osteoarticular $(7,62 \%)$, geniturinário $(4,63 \%)$, cardiovascular $(3,97 \%)$, dentre outros $(5,30 \%)$. As alterações sugerem a ocorrência de doenças e a necessidade de adequação do manejo produtivo ou sanitário nas granjas comerciais, ambicionando a redução de perdas econômicas e o fortalecimento do setor avícola regional.

Palavras-chave: Necropsia; Patologia aviária; Sanidade avícola

\section{ABSTRACT}

The objective of the study was to identify macroscopic lesions in the organs and carcasses of white laying hens from farms in the Agreste region of Pernambuco, and to discuss the possibility of occurrence of diseases. Commercial laying hens were collected up to 12 hours after death and transported to the Laboratory of Anatomy and Animal Pathology of the Academic Unit of Garanhuns, Federal Rural University of Pernambuco. Detailed anamnesis was performed with handlers and veterinarians from their respective farms, with questions about the lot of hens. Macroscopic alterations were observed in the external area, celomous cavity and organs of 176 laying hens, of four farms. Of these hens, $146(82.95 \%)$ presented some necropsy findings, mainly in the digestive $(40.73 \%)$ and respiratory $(37.75 \%)$ systems. Changes were also observed in the osteoarticular $(7.62 \%)$, genitourinary $(4.63 \%)$, cardiovascular $(3.97 \%)$, among others $(5.30 \%)$ systems. The changes suggest the occurrence of diseases and the need to adapt the productive or sanitary management in commercial farms, aiming to reduce economic losses and strengthen the regional poultry sector.

keywords: Necropsy; Avian pathology; Poultry health 
ALMEIDA, T.J.O.; SANTOS FILHO, A.A.; MACIEL, C.E.M.; ROLIM, M.B.Q.

Lesões macroscópicas em órgãos e carcaças de poedeiras comerciais do Agreste de Pernambuco, Brasil

\section{Introdução}

A produção comercial de ovos de consumo é uma atividade de grande representatividade no agronegócio brasileiro. Segundo estimativas do Instituto Brasileiro de Geografia e Estatística - IBGE, no ano de 2017 foram produzidas mais de 4,2 bilhões de dúzias de ovos de galinha no Brasil, das quais 16,10\% (683,299 milhões de dúzias) na região Nordeste do país. Os estados de Pernambuco e Ceará responderam por mais da metade da produção nordestina, tendo em vista a estimativa de, respectivamente, $35,17 \%$ (240,319 milhões de dúzias) e 26,02\% (177,766 milhões de dúzias) da produção regional (IBGE, 2019).

A qualidade dos ovos pode ser influenciada por diversos fatores, incluindo ambiência, genética e sanidade das aves, que são grandes desafios na produção avícola (Barbosa et al., 2008). A ocorrência de doenças é uma realidade em determinados lotes, especialmente quando negligenciadas as medidas de biosseguridade, bem como o manejo sanitário. A não investigação possibilita o subdiagnóstico e, consequentemente, a subnotificação das enfermidades, o que dificulta a sua prevenção e coloca em riscos a sanidade avícola e saúde pública (Silva et al., 2014).

Vários exames podem ser realizados para diagnosticar enfermidades que acometem aves, incluindo sorológico, bacteriológico, virológico, parasitológico, fúngico, molecular, histopatológico e necroscópico (Cardoso; Tessari, 2015). Necropsia (do grego nekros: morte ou cadáver, e opsis: ação de ver ou examinar) é a inspeção visual detalhada e metódica das cavidades e órgãos do animal, com o objetivo de investigar a respectiva causa mortis (Gonçalves; Salgado, 2011).

Determinados sinais e/ou lesões verificados na necropsia de aves sugerem a necessidade de exames complementares, ambicionando o diagnóstico definitivo das enfermidades. Entretanto, os resultados da necropsia, juntamente com a anamnese, permitem um diagnóstico presuntivo (Cardoso, 2002). Desta forma, o estudo teve como objetivo identificar lesões macroscópicas em órgãos e carcaças de poedeiras comerciais brancas, de granjas avícolas do Agreste de Pernambuco, e discutir a possibilidade de ocorrência de doenças.

\section{Material e métodos}

No ano de 2017 foram coletadas aves poedeiras brancas de granjas comerciais da mesorregião Agreste de Pernambuco, particularmente dos municípios de Angelim, Brejão e São Bento do Una, até 12 horas após o óbito. Nesse momento, acondicionadas em isopor com gelo e imediatamente transportadas ao setor de necropsia do Laboratório de Anatomia e Patologia Animal da Unidade Acadêmica de Garanhuns, Universidade Federal Rural de Pernambuco (UAG/UFRPE).

A avaliação necroscópica das aves foi realizada conforme Coelho (2006). Inicialmente, seccionou-se as articulações coxofemoral, tendo em vista a estabilização da ave em decúbito dorsal na mesa de necropsia, e avaliou-se suas condições gerais de saúde e nutricionais. Em seguida, de acordo com a região/órgão estudado, avaliou-se tamanho, coloração, odor, consistência, resistência e mineralização, bem como a existência e características de secreções, lesões e parasitos. Durante o exame externo da ave, avaliou-se pele, cavidades naturais, olhos e conjuntivas, bico, penas, 
ALMEIDA, T.J.O.; SANTOS FILHO, A.A.; MACIEL, C.E.M.; ROLIM, M.B.Q.

Lesões macroscópicas em órgãos e carcaças de poedeiras comerciais do Agreste de Pernambuco, Brasil

glândula uropigiana, bursa de Fabricius e membros posteriores. Enquanto na cavidade celomática, avaliou-se estruturas internas, incluindo sacos aéreos, proventrículo, ventrículo, fígado, baço, intestinos, coração, pulmões, rins, ovários e oviduto.

Anamnese minuciosa, relativa ao lote de origem da ave, foi realizada com tratadores dos aviários e médicos veterinários das respectivas granjas. Os dados da necropsia e informações da anamnese foram tabulados e analisados por meio de estatística descritiva (Microsoft Excel, Microsoft,

15.0, Office 2013), pela determinação da média, frequência absoluta e relativa (Sampaio, 2002).

\section{Resultados e discussão}

Um total de 176 poedeiras mortas foram coletadas em granjas de postura comercial do Agreste de Pernambuco. Desse total, 68,75\% (121 aves) pertencentes à Granja 1 - G1, localizada no município de Angelim; 17,05\% (30) à Granja 2 - G2, município de Brejão; 6,25\% (11) e 7,95\% (14) às Granjas 3 e 4 - G3 e G4, respectivamente, localizadas no município de São Bento do Una. Na avaliação necroscópica, a maioria das aves $(82,95 \%)$ apresentou alguma alteração macroscópica (Tabela 1).

Tabela 1 - Quantitativo de achados de necropsia por sistema em poedeiras comerciais do Agreste de Pernambuco, em 2017

\begin{tabular}{|c|c|c|c|c|c|c|c|c|c|c|}
\hline \multirow{2}{*}{ Sistema } & \multicolumn{2}{|c|}{ G1 } & \multicolumn{2}{|c|}{ G2 } & \multicolumn{2}{|c|}{ G3 } & \multicolumn{2}{|c|}{ G4 } & \multicolumn{2}{|c|}{ Total } \\
\hline & $\mathrm{N}$ & $\%$ & $\mathbf{N}$ & $\%$ & $\mathbf{N}$ & $\%$ & $\mathbf{N}$ & $\%$ & $\mathbf{N}$ & $\%$ \\
\hline Digestório & 99 & 50,51 & $\begin{array}{l}1 \\
7\end{array}$ & 25,37 & 7 & 30,43 & 0 & 0 & 123 & $\begin{array}{c}40,7 \\
3\end{array}$ \\
\hline Respiratório & 74 & 37,76 & $\begin{array}{l}2 \\
3\end{array}$ & 34,33 & 9 & 39,13 & 8 & 50 & 114 & $\begin{array}{c}37,7 \\
5\end{array}$ \\
\hline Osteoarticular & 10 & 5,1 & 7 & 10,45 & 2 & 8,7 & 4 & 25 & 23 & 7,62 \\
\hline Geniturinário & 2 & 1,02 & 9 & 13,43 & 1 & 4,35 & 2 & 12,5 & 14 & 4,63 \\
\hline $\begin{array}{l}\text { Cardiovascular } \\
\text { Outros }\end{array}$ & $\begin{array}{l}4 \\
7\end{array}$ & $\begin{array}{l}2,04 \\
3,57\end{array}$ & $\begin{array}{l}5 \\
6\end{array}$ & $\begin{array}{l}7,46 \\
8,96\end{array}$ & $\begin{array}{l}3 \\
1\end{array}$ & $\begin{array}{c}13,04 \\
4,35\end{array}$ & $\begin{array}{l}0 \\
2\end{array}$ & $\begin{array}{c}0 \\
12,5\end{array}$ & $\begin{array}{l}12 \\
16\end{array}$ & $\begin{array}{l}3,97 \\
5,30\end{array}$ \\
\hline Total & $\begin{array}{c}19 \\
6\end{array}$ & 100 & $\begin{array}{l}6 \\
7\end{array}$ & 100 & $\begin{array}{l}2 \\
3\end{array}$ & 100 & $\begin{array}{l}1 \\
6\end{array}$ & 100 & $\begin{array}{c}30 \\
2\end{array}$ & 100 \\
\hline
\end{tabular}

G1=Granja 1; G2=Granja 2; G3=Granja 3; G4=Granja 4; N=Número de achados de necropsia; \%=Percentual de achados de necropsia. Fonte: Pesquisa direta.

Apesar da variação entre as granjas na frequência dos sistemas acometidos, a maioria dos achados foi atribuída ao sistema digestório $(40,43 \%)$ e respiratório $(37,75 \%)$. Contudo, os achados do sistema digestório foram os mais frequentes na $\mathrm{G} 1$, enquanto os achados do sistema respiratório, mais frequentes na G2, G3 e G4. Particularmente na G4, nenhuma ave apresentou achado no sistema digestório, sendo o sistema osteoarticular o segundo mais acometido. 0 resultado dos achados por sistema pode então direcionar o trabalho de sanidade em cada granja, que deverá focar nos sistemas mais acometidos. 
ALMEIDA, T.J.O.; SANTOS FILHO, A.A.; MACIEL, C.E.M.; ROLIM, M.B.Q.

Lesões macroscópicas em órgãos e carcaças de poedeiras comerciais do Agreste de Pernambuco, Brasil

Secreção nasal mucopurulenta, relacionada ao sistema respiratório, foi identificada em mais da metade das aves (59,09\%), o que representou $34,44 \%$ do total de achados e classificou-a como o principal achado de necropsia (Tabela 2). Este resultado é esperado, uma vez que as doenças respiratórias são comuns nas regiões de maior concentração de aves de postura (Buim et al., 2006).

Tabela 2 - Achados de necropsia em poedeiras comerciais do Agreste de Pernambuco, em 2017.

\begin{tabular}{|c|c|c|c|c|c|c|c|c|}
\hline \multirow[t]{2}{*}{ Sistema } & \multirow[t]{2}{*}{ Achado de necropsia } & \multirow{2}{*}{$\frac{\mathrm{G} 1}{\mathrm{~N}}$} & \multirow{2}{*}{$\frac{\mathrm{G} 2}{\mathrm{~N}}$} & \multirow{2}{*}{$\frac{\mathrm{G} 3}{\mathrm{~N}}$} & \multirow{2}{*}{$\frac{\mathrm{G} 4}{\mathrm{~N}}$} & \multicolumn{3}{|c|}{ Total } \\
\hline & & & & & & $\mathrm{N}$ & $\%$ & \%AA \\
\hline \multirow[t]{5}{*}{ Respiratório } & Secreção nasal mucopurulenta & 70 & 18 & 8 & 8 & 104 & 34,44 & $\begin{array}{l}59,0 \\
9\end{array}$ \\
\hline & Hemorragia pulmonar & 4 & 2 & - & - & 6 & 1,99 & 3,41 \\
\hline & Aerossaculite & - & 1 & 1 & - & 2 & 0,66 & 1,37 \\
\hline & Edema pulmonar & - & 1 & - & - & 1 & 0,33 & 0,57 \\
\hline & Amarelamento pulmonar & - & 1 & - & - & 1 & 0,33 & 0,57 \\
\hline \multirow[t]{7}{*}{ Digestório } & Hepatomegalia & 50 & 7 & 2 & - & 59 & 19,54 & $\begin{array}{l}33,5 \\
2\end{array}$ \\
\hline & Esplenomegalia & 43 & 4 & 1 & - & 48 & 15,90 & $\begin{array}{l}27,2 \\
7\end{array}$ \\
\hline & Necrose focal hepática & 5 & 1 & 2 & - & 8 & 2,65 & 4,55 \\
\hline & Lipidose hepática & 1 & 3 & 1 & - & 5 & 1,66 & 2,84 \\
\hline & Perihepatite & - & 1 & - & - & 1 & 0,33 & 0,57 \\
\hline & Coilina enegrecida & - & - & 1 & - & 1 & 0,33 & 0,57 \\
\hline & Torção jejunal & - & 1 & - & - & 1 & 0,33 & 0,57 \\
\hline \multirow[t]{2}{*}{ Osteoarticular } & Fratura da cabeça do fêmur & 10 & 5 & 1 & 4 & 20 & 6,63 & $\begin{array}{l}11,3 \\
6\end{array}$ \\
\hline & Erosão da cabeça do fêmur & - & 2 & 1 & - & 3 & 0,99 & 1,70 \\
\hline \multirow[t]{6}{*}{ Geniturinário } & Postura abdominal & 1 & 4 & - & 1 & 6 & 1,99 & 3,41 \\
\hline & Prolapso cloacal & - & 2 & - & 1 & 3 & 0,99 & 1,70 \\
\hline & Gema hemorrágica & 1 & 1 & - & - & 2 & 0,66 & 1,37 \\
\hline & Nefromegalia & - & 1 & - & - & 1 & 0,33 & 0,57 \\
\hline & Salpingite & - & - & 1 & - & 1 & 0,33 & 0,57 \\
\hline & Líquido no oviduto & - & 1 & - & - & 1 & 0,33 & 0,57 \\
\hline \multirow[t]{4}{*}{ Cardiovascular } & Cardiomegalia & 1 & 3 & 1 & - & 5 & 1,66 & 2,84 \\
\hline & Sufusão ventricular & 3 & - & - & - & 3 & 0,99 & 1,70 \\
\hline & Pericardite & - & 1 & 2 & - & 3 & 0,99 & 1,70 \\
\hline & Hipertrofia atrial e ventricular & - & 1 & - & - & 1 & 0,33 & 0,57 \\
\hline \multirow[t]{6}{*}{ Outros } & Canibalismo & 4 & 2 & - & - & 6 & 1,99 & 2,27 \\
\hline & Hemorragia celomática & 2 & 1 & - & - & 3 & 0,99 & 1,70 \\
\hline & Ascite & 1 & 1 & - & 1 & 3 & 0,99 & 1,70 \\
\hline & Peritonite & - & - & 1 & 1 & 2 & 0,66 & 1,37 \\
\hline & Caquexia & - & 1 & - & - & 1 & 0,33 & 0,57 \\
\hline & $\begin{array}{l}\text { Lesões granulomatosas } \\
\text { disseminadas }\end{array}$ & - & 1 & - & - & 1 & 0,33 & 0,57 \\
\hline Total & - & 196 & 67 & 23 & 16 & 302 & 100 & - \\
\hline
\end{tabular}

G1=Granja 1; G2=Granja 2; G3=Granja 3; G4=Granja 4; N=Número de achados de necropsia; \%=Percentual de achados de necropsia; \%AA= Percentual de Aves necropsiadas com determinado Achado. Fonte: Pesquisa direta.

Durante a anamnese, os médicos veterinários abordaram e exemplificaram a importância das doenças respiratórias nas granjas comerciais estudadas. Com isso, o manejo sanitário e vacinal, nas respectivas granjas, objetivavam também a sua prevenção. A exemplo disto, verificou-se o 
ALMEIDA, T.J.O.; SANTOS FILHO, A.A.; MACIEL, C.E.M.; ROLIM, M.B.Q.

Lesões macroscópicas em órgãos e carcaças de poedeiras comerciais do Agreste de Pernambuco, Brasil

criterioso programa vacinal, o qual imunizava o lote frente a diversas doenças respiratórias, como bronquite infecciosa, doença de Newcastle, pneumovirose e coriza infecciosa. Apesar da prática de vacinação não evitar a ocorrência de doenças, permite a sua prevenção, mediada pela produção de anticorpos específicos para determinados micro-organismos patogênicos.

A presença de secreção e descarga nasal é um achado sugestivo de bronquite infecciosa, micoplasmose, doença de Newcastle e coriza infecciosa. Contudo, o achado pode estar relacionado à distintas doenças respiratórias, incluindo influenza aviária, pneumovirose, laringotraqueíte infecciosa e pasteurelose (CDPA, 2017). Diante da importância dessas enfermidades no Brasil, com exceção da pneumovirose, todas são de notificação compulsória no Sistema Nacional de Informações Zoossanitárias - SIZ (Brasil, 2019). Influenza aviária, doença de Newcastle e laringotraqueíte infecciosa requerem notificação imediata de qualquer caso suspeito, enquanto micoplasmose, notificação imediata de caso confirmado e pasteurelose, bronquite e coriza infecciosa, notificação mensal de casos confirmados (Brasil, 2013).

Bronquite infecciosa das galinhas é uma doença primariamente respiratória, altamente contagiosa, causada pelo coronavírus (Pena et al., 2005). Além da redução na produção e qualidade dos ovos, a ave doente pode apresentar diferentes alterações, incluindo nefromegalia e exsudato seroso, catarral ou caseoso na traqueia, vias aéreas e sinusoides (Cubillos, 2009). Neste sentido, foi observado que uma ave estudada apresentou exsudato nasal e, simultaneamente, nefromegalia. Além disso, foi relatado que bronquite infecciosa já ocorreu em todas as granjas do estudo, ocasionando problemas na qualidade dos ovos. Apesar dos médicos veterinários desconhecerem a sua ocorrência no momento da anamnese, a possibilidade não pode ser descartada.

Micoplasmose é uma das doenças mais importantes no setor avícola, pelo seu impacto econômico. A doença é de caráter crônico endêmico e seus sinais e lesões nas aves podem ser intensificados pelo sinergismo com outros agentes patogênicos (Buim et al., 2006). Dentre as espécies de micoplasmas, apenas quatro são de importância econômica para avicultura: Mycoplasma gallisepticum, M. synoviae, M. iowae e M. meleagridis, sendo a última importante para perus. De forma geral, são observados muco ou exsudato catarral nas narinas, traqueia e pulmões e edema e/ou aerossaculite. Em maior frequência quando os agentes da doença estão associados a outros patógenos, como Escherichia coli, a doença também resulta em pericardite, perihepatite e salpingite (Mettifogo; Ferreira, 2009), lesões que também foram observadas em algumas aves do presente estudo, as quais estavam associadas às secreções nasais.

Doença de Newcastle, causada por vírus do sorotipo Paramyxovirus aviário tipo 1 (APMV-1), é uma importante enfermidade de carácter zoonótico, que pode causar severa mortalidade em lotes susceptíveis. 0 quadro clínico está relacionado, principalmente, a alterações no sistema respiratório e neurológico e sua severidade depende da cepa viral envolvida. Cepa velogênica provoca severa enfermidade, com alta mortalidade superaguda, enquanto cepa mesogênica, menos severa e raramente atinge o Sistema Nervoso Central (SNC), e lentogênica, com moderadas alterações respiratórias e queda na produção. Principalmente quando a doença é causada por uma cepa lentogênica, o quadro clínico é de alterações inespecíficas, as quais podem ocorrer em outras doenças respiratórias, dificultando o diagnóstico presuntivo (Coelho, 2006; Fernandes et al., 2013). 
ALMEIDA, T.J.O.; SANTOS FILHO, A.A.; MACIEL, C.E.M.; ROLIM, M.B.Q.

Lesões macroscópicas em órgãos e carcaças de poedeiras comerciais do Agreste de Pernambuco, Brasil

Coriza infecciosa é uma doença respiratória aguda e crônica, causada pelo Avibacterium paragallinarum, de grande importância para a avicultura industrial, principalmente nas granjas de postura comercial (Santos et al., 2009). As aves acometidas podem apresentar a cabeça inchada, pelo edema subcutâneo, e secreção nasal com odor fétido (CDPA, 2017), alterações não verificadas nas aves necropsiadas. Contudo, secreção nasal pode cursar com aerossaculite, o que foi verificado em duas aves. Apesar dos relatos de vacinação regular para a coriza infecciosa, diante os sinais clínicos, esta também é uma doença sugestiva.

Influenza aviária é uma enfermidade de grande importância para avicultura mundial, causada por vírus da família Orthomyxoviridae, gênero Influenzavirus Tipo A. O quadro clínico é dependente da patogenicidade do vírus envolvido, que pode ser de alta, média ou baixa patogenicidade. Algumas possíveis alterações em aves, incluindo exsudato mucopurulento, aerossaculite e peritonite, foram verificadas no presente estudo. Por outro lado, não verificou-se outras importantes alterações, como pancreatite, lesões congestivas e hemorrágicas na pele e órgãos (Alexander, 2009; Tocantins, 2019), o que reduz a sua possibilidade. No mais, não há relato de influenza aviária no Brasil, seja em aves comerciais, migratórias ou na população humana, o que aponta a necessidade do constante monitoramento.

Pneumovirose, causada pelo pneumovírus aviário, está relacionada a duas enfermidades que apresentam sinais clínicos similares, a síndrome da cabeça inchada em galinhas e a rinotraqueíte dos perus (Santos et al., 2009). A doença provoca, especialmente em matrizes e poedeiras, um quadro respiratório com secreção nasal mucoide, aquosa ou turva. 0 acúmulo da secreção gera o edema facial e submandibular, caracterizando a cabeça inchada. Sinais neurológicos e queda na produção e qualidade dos ovos também são achados comuns. Ainda, dentre outras lesões, pode haver pericardite, perihepatite e aerossaculite (Cook, 2009; Santos et al., 2009). Pneumovirose foi listada no histórico de doenças, em todas as granjas estudadas. Particularmente na G3, foi relatado um surto com consequências graves em torno de dois meses antes da anamnese.

$\mathrm{Na}$ laringotraqueíte, causada por vírus da família Herpesviridae, há um processo inflamatório na traqueia, de consistência mucoide a hemorrágica. Contudo, traqueíte não foi verificada no presente estudo. Além disso, a doença normalmente apresenta alta morbidade, de até $70 \%$, o que facilita sugerir a ocorrência da doença, quando presente (Santos et al., 2009).

Pasteurelose é uma doença septicêmica, caracterizada por lesões hemorrágicas e provocada pela Pasteurella multocida (Santos et al., 2009). Na forma aguda, as lesões estão associadas a distúrbios vasculares, mas também descargas nasais. Segundo Knobl (2009), outras possíveis alterações incluem necrose focal hepática, a qual estava associada a descargas nasais em uma ave estudada; hemorragia na cavidade celomática, também em uma ave; e hepato ou esplenomegalia, em 26 aves. Enquanto a forma crônica, de caráter fibrinoso, supurativo e necrosante, ocasiona um maior comprometimento respiratório, com exsudação catarral nas vias aéreas. Contudo, não verificou-se outras alterações características da forma crônica, como pneumonias, exsudato ou massa caseosa nas articulações, edema de face e meningite (Knobl, 2009).

Hemorragia pulmonar, verificada em $6(3,41 \%)$ aves necropsiadas, foi o segundo principal achado no sistema respiratório. Enquanto as demais alterações respiratórias, aerossaculite, edema 
ALMEIDA, T.J.O.; SANTOS FILHO, A.A.; MACIEL, C.E.M.; ROLIM, M.B.Q.

Lesões macroscópicas em órgãos e carcaças de poedeiras comerciais do Agreste de Pernambuco, Brasil

pulmonar e amarelamento pulmonar, verificadas em apenas uma ou duas aves (Tabela 2). Tal hemorragia resulta de congestão pulmonar, que pode ser ativa, quando originada de processos irritativos, incluindo o excesso de cansaço físico, inspiração de gases tóxicos, inspiração de ar quente ou frio ou exposição ao tempo quente ou frio. Mas também passiva, quando a causa é de origem mecânica, incluindo obstáculo para o fluxo circulatório. Muitas vezes, a lesão resulta no óbito das aves, por síncope cardíaca ou asfixia, quando há redução no campo de hematose, o que prejudica a transformação do sangue venoso em arterial (Malavazzi, 1999).

Algumas alterações no sistema digestório foram de grande importância e frequência, como hepatomegalia e esplenomegalia, observadas em $33,52 \%$ e $27,27 \%$ das aves, respectivamente. No entanto, 25,57\% das poedeiras apresentaram ambas alterações, o que caracteriza uma hepatoesplenomegalia. Enquanto necrose focal hepática, normalmente associada ao processo septicêmico em aves, verificada em 4,55\% das aves (CDPA, 2017) e lipidose hepática, relacionada ao acúmulo de gordura nos hepatócitos, em 2,84\%. As demais alterações, perihepatite, coilina enegrecida e torção jejunal, foram identificadas em apenas uma ave cada (Tabela 2).

Hepatomegalia é uma lesão associada ao aumento do fígado e pode acontecer em diversas enfermidades aviárias. Dentre estas, doença de Marek e leucose linfoide, quando o fígado, além de aumentado, comumente fica pálido e com nodulações. Enquanto na salmonelose, pode haver hepatomegalia associada a necrose focal hepática, de coloração marrom-esverdeada, lesões estas, identificadas em uma ave necropsiada. Por sua vez, o aumento do baço, lesão conhecida como esplenomegalia, também pode sinalizar diversas enfermidades, incluindo doença de Marek, leucose linfoide, salmonelose, Doença Infecciosa da Bursa (D.I.B.), viremia, cólera aviária e outras septicemias (Guahyba, 2002). Neste sentido, algumas doenças cursam com hepatoesplenomegalia. Contudo, com exceção de salmonelose, não foram observadas alterações características que reforçassem a possibilidade de tais enfermidades.

Lesões osteoarticulares foram identificadas em algumas aves necropsiadas, o que ratifica a sua importância nas granjas estudadas. Fratura e erosão da cabeça do fêmur foram observadas nas articulações coxofemoral, de 11,36\% e 1,70\% das aves necropsiadas, respectivamente (Tabela 2). Dentre outras causas, resultam de processo necrótico da cabeça do fêmur e em menor frequência, osteomielite (Guahyba, 2002). Por outro lado, em relação ao sistema geniturinário, postura abdominal $(3,41 \%)$ foi o principal achado de necropsia, seguido pelo prolapso cloacal $(1,70 \%)$. Postura abdominal está relacionada a presença de gema livre na cavidade celomática e é um acidente relativamente comum em poedeiras, especialmente no período do pico de produção (CDPA, 2017).

As principais alterações cardiovasculares foram cardiomegalia, pericardite e sufusão ventricular. Tais lesões podem resultar, dentre outras enfermidades, da síndrome ascítica, o que não foi o caso do presente estudo, uma vez que não se verificou ascite nas aves que apresentaram as alterações cardiovasculares (Guahyba, 2002). Enquanto em outros sistemas (Tabela 2), alterações foram menos frequentes, as quais identificadas na cavidade celomática ou outras regiões. A exemplo disto, evidenciou-se canibalismo em 6 aves necropsiadas, quando havia sangue nas penas, principalmente da região cloacal. Enquanto em uma ave, observou-se lesões granulomatosas 
ALMEIDA, T.J.O.; SANTOS FILHO, A.A.; MACIEL, C.E.M.; ROLIM, M.B.Q.

Lesões macroscópicas em órgãos e carcaças de poedeiras comerciais do Agreste de Pernambuco, Brasil

disseminadas, com aspecto de couve-flor, no ovário, útero, mesentério e lúmen do duodeno, o que sugere a ocorrência de coligranulomatose ou tuberculose aviária (CDPA, 2017).

A realização de anamnese possibilitou importantes informações acerca do manejo nas granjas avícolas estudadas. Foram citadas vacinações para doença de Marek, doença de Newcastle, pneumovirose, síndrome da queda de postura, D.I.B., salmonelose por Salmonella enterica subspécie enterica sorovar Enteritidis, bronquite e coriza infecciosa, as duas últimas realizadas regularmente. Quanto ao histórico de doenças, os médicos veterinários relataram pneumovirose, bronquite infecciosa e bouba aviária, quando, a depender da enfermidade, observou-se alta mortalidade, descargas nasais, cabeça inchada, apatia, sonolência e redução na produção e qualidade dos ovos. Pelo conhecimento destes profissionais, tais problemas não ocorriam no momento da anamnese e coleta das aves.

A necropsia de aves poedeiras comerciais e avaliação das lesões macroscópica permitem sugerir a ocorrência de determinados casos/surtos no plantel. Com base no conhecimento das doenças prevalentes na região, bem como nas informações da anamnese, é possivel direcionar os achados. Contudo, é imprescindível a atualização constante dos profissionais, uma vez que os achados podem estar relacionados à doenças incomuns ou anteriormente exóticas na região (Peixoto; Barros, 1998; Vieira-Pinto et al., 2003). Isto aponta a necessidade de investigação, por meio de exames complementares, para um diagnóstico definitivo, que é fundamental para o seu adequado controle e prevenção, bem como para a notificação nos sistemas de informação em saúde animal.

As lesões apresentadas reforçam a importância da necropsia de poedeiras comerciais, para a avaliação do status sanitário, controle e prevenção das doenças no plantel. Ainda, a importância do médico veterinário na produção avícola, para garantir a biosseguridade dos lotes, bem estar animal, redução do impacto econômico e preservação da saúde pública, visto que algumas das enfermidades sinalizadas, incluindo doença de Newcastle e influenza aviária, apresentam potencial zoonótico.

\section{Conclusões}

Achados de necropsia em poedeiras comerciais brancas, de granjas avícolas do Agreste de Pernambuco, são identificados principalmente nos sistemas respiratório e digestório, mas também em outros sistemas, incluindo osteoarticular, geniturinário e cardiovascular. As alterações sugerem a ocorrência de doenças e a necessidade de adequação do manejo produtivo e/ou sanitário nas granjas de postura comercial, ambicionando a redução de perdas econômicas e o fortalecimento do setor avícola regional.

\section{Agradecimentos}

Aos médicos veterinários e funcionários das granjas avícolas do estudo, pelo fornecimento de informações e de aves mortas, e ao Programa de Iniciação Cientifica Voluntária, da Universidade Federal Rural de Pernambuco (PIC/UFRPE). 


\section{Referências}

ALEXANDER, D.J. Doença de Newcastle. In: REVOLLEDO, L.; FERREIRA, A.J.P. Patologia aviária. Barueri: Manole, 2009. p.219-228.

BARBOSA, N.A.A.; SAKOMURA, N.K.; MENDONÇA, M.O.; FREITAS, E.R.; FERNANDES, J.B.K. Qualidade de ovos comerciais provenientes de poedeiras comerciais armazenados sob diferentes tempos e condições de ambientes. Ars Veterinária, 24:127-133, 2008.

BUIM, M.R.; GUASTALLI, E.A.L.; TOGASHI, C.K.; GAMA, N.M.S.Q.; OLIVEIRA, R.A. Micoplasmose aviária e associações patológicas em aves de postura comercial. Biológico, 68:131-133, 2006.

BRASIL. Ministério da Agricultura, Pecuária e Abastecimento. Sistema de Informação em Saúde Animal. Disponível em: <http://www.agricultura.gov.br/assuntos/sanidade-animal-evegetal/saudeanimal/sistema-informacao-saude-animal>. Acesso em: 10 Jun. 2019.

BRASIL. Ministério da Agricultura, Pecuária e Abastecimento. Instrução Normativa $\mathrm{n}^{\circ} \mathbf{5 0}$, de 24 de setembro de 2013. Lista de doenças de notificação obrigatória ao Serviço Veterinário Oficial. Diário Oficial da União, n. 186, p. 47, 25 Set. 2013. Disponível em: <http://www.agricultura.gov.br/assuntos/sanidade-animal-e-vegetal/saudeanimal/arquivossisa/Listadedoencasanimaisdenotificaoobrigatoria.pdf>. Acesso em: 10 Jun. 2019.

CARDOSO, A.L.S.P.; TESSARI, E.N.C. Cuidados na coleta e envio de amostras para laboratório avícola. Biológico, 77:1-6, 2015.

CARDOSO, V.P. Técnica de necropsia. In: ANDRADE, A.; PINTO, S.C.; OLIVEIRA, R.S. Animais de Laboratório: criação e experimentação. Rio de Janeiro: Editora FIOCRUZ, 2002. p.331-336.

CDPA. Centro de Diagnóstico e Pesquisa em Patologia Aviária. Manual de necropsia. Universidade Federal do Rio Grande do Sul. 14p. Disponível em: <http://www.ufrgs.br/cdpa/images/documentos/manual de necropsia.pdf>. Acesso em: 17 jan.

2018.

COELHO, H. E. Patologia das aves. São Paulo: Editora Tecmedd, 2006. p.3-5.

COOK, J.K.A. Pneumovirose. In: REVOLLEDO, L.; FERREIRA, A.J.P. Patologia aviária. Barueri: Manole, 2009. p.288-295.

CUBILLOS, A. Bronquite infecciosa aviária. In: REVOLLEDO, L.; FERREIRA, A.J.P. Patologia aviária. Barueri: Manole, 2009. p.158-171.

FERNANDES, C.C.; VARANI, A.M.; SILVA, K.R.; SANTOS, F.F.; MONTASSIE M.F.S. Genoma completo de uma estirpe patogênica do vírus da doença de newcastle isolada no Brasil na década de 70 . Ars Veterinária, 29:18, 2013.

GONÇALVES G.A.M.; SALGADO, B.S. Necropsia cosmética em aves. Archives of Veterinary Science, $16: 9-17,2011$.

GUAHYBA, A.S. Sanidade Avícola. Porto Alegre, n. 7, p. 4-5, 2002. Disponível em: <http://www.guahyba.vet.br/trabalhos/trab27.htm>. Acesso em: 18 jan. 2017.

IBGE. Instituto Brasileiro de Geografia e Estatística. Produção da Pecuária Municipal 2016. Disponível em: <https://cidades.ibge.gov.br/brasil/pe/pesquisa/24/27745>. Acesso em: 02 fev. 2018. 
KNOBL, T. Pasteurelose (cólera aviária). In: REVOLLEDO, L.; FERREIRA, A.J. P. Patologia aviária. Barueri: Manole, 2009. p.117-123.

MALAVAZZI, G. Avicultura: manual prático. São Paulo: Nobel, 1999. 156p.

METTIFOGO, E.; FERREIRA, A.J.P. Micoplasmose aviária. In: ANDREATTI FILHO, R.L. Saúde aviária e doenças. São Paulo: Roca, 2006. p.18-19.

PEIXOTO, P.V.; BARROS, C.S.L.A. importância da necropsia em medicina veterinária. Pesquisa Veterinária Brasileira, 18:1-4, 1998.

PENA, L.J.; SANTOS, B.M.; ROBERTI, R.P.; MARIN, S.Y. Bronquite infecciosa das galinhas. Arquivos do Intituto Biológico, 72:397-404, 2005.

SAMPAIO, I.B.M. Estatística Aplicada à Experimentação Animal. 2 ed. Belo Horizonte: Fundação de Estudo e Pesquisa em Medicina Veterinária e Zootecnia, 2002. 265p.

SANTOS, B.M.; PEREIRA, C.G.; GÓMEZ, S.Y.M.; ABREU, T.G.M. Prevenção e controle de doenças infecciosas nas aves de produção. Viçosa: Editora UFV, 2009. 150p.

SILVA, V.A.S.; KIM, P.C.P.; BARROS, M.R.; VILELA, S.M.O.; SILVA, L.B.G.; MOTA, R.A. Identificação de Avibacterium paragallinarum em frangos de corte e poedeiras comerciais no estado de Pernambuco. Pesquisa Veterinária Brasileira, 34:819-821, 2014.

TOCANTINS. Agência de Defesa Agropecuária de Tocantins. Influenza aviária. Disponível em: <https://adapec.to.gov.br/animal/sanidade-animal/influenza-aviaria/>. Acesso em: 10 Jun. 2019.

VIEIRA-PINTO, M.; MATEUS, T.; SEIXAS, F.; FONTES, M.C.; MARTINS, C. O papel da inspecção sanitária post mortem em matadouro na detecção de lesões e processos patológicos em aves. Quatro casos de lesões compatíveis com a doença de Marek em carcaças de aves rejeitadas. Revista Portuguesa de Ciências Veterinárias, 98:145-148, 2003. 